\title{
Formation and Evaluation of Costs for Geotechnical Monitoring
}

\author{
Tatiana Konoreva ${ }^{1, *}$, Olesia Miliushenko ${ }^{1}$, and Oksana Kovaleva ${ }^{2}$ \\ ${ }^{1}$ Financial University under the Government of the Russian Federation, Omsk Branch, 644099 \\ Partizanskaya st. 6, Omsk, Russia \\ ${ }^{2}$ Omsk Scientific Center of the Siberian Branch of the Russian Academy of Sciences, 644024 Karl \\ Marx st., 15, Omsk, Russia
}

\begin{abstract}
In this paper, the features of a set of works on geotechnical monitoring as an object of cost accounting are identified. The factors that determine the specifics of various geotechnical monitoring agreements that affect related costs are studied. The modern practice of the formation and accounting of costs for geotechnical monitoring in the exploring and mining organizations is investigated. The expediency of applying the project method of accounting and cost estimation for a complex of geotechnical monitoring works is substantiated. Using of appropriate documentary forms of accounting and cost estimation for the implementation of geotechnical monitoring in organizations engaged in geotechnical monitoring is recommended.
\end{abstract}

\section{Introduction}

Currently, most CEO in Russia have finally realized the importance of cost management at industrial enterprises. Development and application of advanced methods of cost management, including their research and evaluation, will allow companies to achieve sustainable effective of enterprises' functioning in unstable and crises conditions. The purpose of this study is to develop a methodology for the research of formation and assessment of costs for geotechnical monitoring. Geotechnical monitoring carried out during the construction of facilities for the mining industry, significantly affects the amount of investment costs.

To achieve the goal of research, the regulatory framework for conducting geotechnical monitoring and the formation of estimates for geotechnical monitoring projects was investigated, in particular, the State Estimated Norm "Reference Book of Basic Prices for Measuring Work and Inspection of Buildings and Structures" (SBTSP 81-02-25-2001) [1] was studied; Collection 3.6 "Inspection and monitoring of the technical condition of building structures and engineering equipment of buildings and structures. MPP-3.6-16" [2]; "A collection of basic prices for work on the examination and monitoring of the technical condition of building structures and engineering equipment of buildings and structures, including subway structures within the zones of influence of construction objects, carried out with the involvement of the budget of the city of Moscow; MPP-3.2.05.07-15", developed

\footnotetext{
*Corresponding author: omsk@,fa.ru
} 
by the specialists of GAU "NIAC" with the participation of specialists of the State Unitary Enterprise "Mosgeorgeotrest", OJSC" MNIITEP ", OJSC "MoszhilNIIproekt", a branch of JSC "TsNIIS" Research Center "Tunnels and Undergrounds" [3]. The compilation is an integral part of the Unified regulatory framework of the Moscow Regional Recommendations (MRR).

Based on expert assessments and our own analytical conclusions, factors and problems of determining the cost of geotechnical monitoring work have been identified. The study of a large number of contracts for the implementation of geotechnical monitoring, formed under these budget estimates, as well as a study of the financial results of the companies performing such work, allowed the authors to draw analytical conclusions and practical recommendations for the reasonable formation and assessment of costs in this industry.

\section{Materials and Methods}

Geotechnical monitoring is a set of works based on field observations of the behavior of structures of a newly erected or reconstructed facilities, its foundation, including the soil mass surrounding the structure, and structures of facilities surrounding buildings, carried out during the construction period and at the initial stage of operation of newly constructed or reconstructed objects [2]. The program of geotechnical monitoring of the construction site determines the composition, volume, frequency and methods of work, taking into account engineering surveys at the construction site, design decisions of the constructed or reconstructed structure and surrounding buildings, the sequence of construction works, etc. As a rule, geotechnical monitoring includes the following works [4].

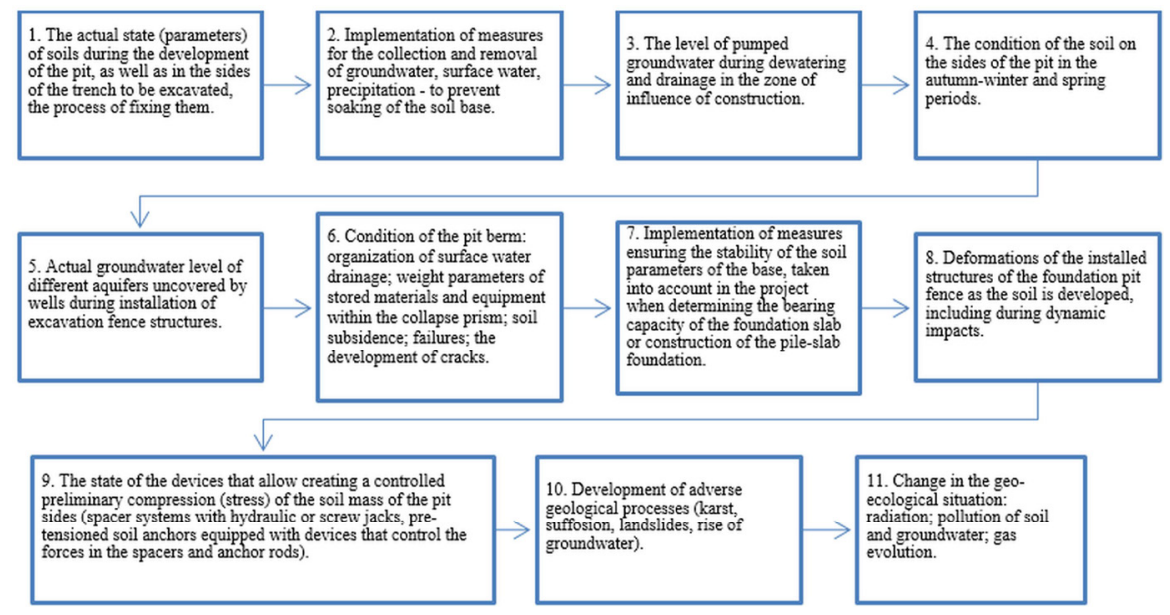

Fig. 1. The main works of geotechnical monitoring.

Thus, the scope of work on geotechnical monitoring depends on many external parameters and is not strictly regulated by law; the program of events is determined by agreement between the customer and the contractor [5-6]. When forming the estimate of the geotechnical monitoring project, organizations are faced with the problem of the lack of a single generally accepted collection of basic prices for the inspection of buildings and structures [3]. As a result, the negotiation process for the contract price may be complicated [7-8]. To determine the cost of geotechnical monitoring, MPR-3.2.05.07-15 [4] provides basic prices for survey (visual-instrumental), engineering and geodetic works.

The base prices of this Collection are not taken into account and are calculated additionally for the corresponding collections of costs: a) for special events during the 
examination of complex structures or facilities; b) for restoration of damaged lawns and green spaces, restoration of damaged concrete and asphalt pavements; c) for restoration of exposed structures; d) for drilling and driving operations during the inspection of foundations, experimental and laboratory work related to the study of engineering-and-geological and hydrogeological conditions of the site; e) on the arrangement and dismantling of scaffolds; f) to determine the planning and altitude position of building structures and geological engineering workings (except for base prices for monitoring the technical condition of buildings and structures within zones of buildings and natural and technological shocks).

Base prices also does not include associated costs: for updating design decisions and making other changes to the developer's documentation related to the introduction of new regulatory documents, making changes to the terms of reference or design assignment, etc. [9-10]

In the methodology for determining the cost of construction products MDS 81-35.2004 there are no instructions on the procedure for assessing the costs of geotechnical monitoring. At the same time, the Geotechnical Monitoring section is included in the List of codes of practice, the application of which ensures compliance with Federal Law No. 384 of December 30, 2009, Technical Regulation on the Safety of Buildings and Structures [4]. A contradiction arises: the design documentation includes a geotechnical monitoring program, and these costs are excluded from the cost set in the consolidated estimated cost of construction. In accordance with CR 22.13330.2011 "Code of practice. Foundations of buildings and structures" (updated edition of CNR 2.02.01-83) during the construction period and at the initial stage of operation of newly constructed or reconstructed objects, geotechnical monitoring is carried out. Geotechnical monitoring is observed in accordance with the program, which is developed during the design process and is a section of the approved part of the design documentation. The costs of geotechnical monitoring are determined by calculation on the basis of design decisions and the observation program and are included in chapter 9 "Other works and costs" of the consolidated estimated calculation of construction costs (columns 7 and 8). In this regard, it is possible to determine specific factors affecting the costs and their formation for geotechnical monitoring. The need for scientific and technical support involves attracting highly qualified personnel to perform such work, and ensuring decent wages and social bonuses.

To the greatest extent, geotechnical monitoring is carried out under special conditions of construction and design (as a rule, areas of the Far North and areas of sparsely distributed permafrost). These conditions determine the remoteness of the objects of work, and, consequently, the increasing amount of travel, transportation costs. Lack of accommodation infrastructure means the cost of organizing life support. Thus, the identified specific factors and the regulatory framework for determining the cost of geotechnical monitoring can determine that this activity, as an object of cost accounting, is a project (work on a specific contract with the customer). Accordingly, in view of this, we perform further practical research and recommendations.

According to the authors, the optimal method of cost accounting for geotechnical monitoring in a company may be the carrier accounting, which involves the determination of all costs associated with the production of a unit of a particular product or the execution of a specific order. The specifics of the activity involves the organization of cost accounting for carriers - projects - specific geotechnical monitoring agreements with customers. Using the normative coefficient for the distribution of overhead costs will save labor costs in the direct distribution of these costs under geotechnical monitoring agreements. The standard coefficient based on the calculation may vary from 13 to $15 \%$ of the distribution base (labor costs). Thus, it is only within the framework of production accounting that it is possible to calculate the unit cost of production, the profit attributable to it and the level of profitability 
- the self-cost of the project - a specific contract for geotechnical monitoring. Therefore, for such companies it is important to introduce accounting management system.

\section{Results and Discussion}

For the most effective process of estimating the costs of geotechnical monitoring, it is advisable at the first stage to plan the cost of work based on the project approach. For this, it is recommended that a hierarchical structure of the project work be compiled and a description of the resources necessary for the implementation of each work be described. Documentation is possible in the following form (Tab. 1).

Table 1. Operations Resources.

\begin{tabular}{|c|c|c|c|c|}
\hline No & $\begin{array}{c}\text { The name of the } \\
\text { operation }\end{array}$ & Resource Type & Amount & $\begin{array}{c}\text { Resource } \\
\text { Availability }\end{array}$ \\
\hline 1 & & & & \\
\hline
\end{tabular}

Type of resource means personnel (indicating the position and hourly wage rate), fixed asset (name), materials, services of third-party organizations. This form should reflect the date from which the resource should be available for a specific project operation, and the period during which the resource should be allocated for this operation. To summarize the costs of the project, it is recommended that a summary estimate of the project costs be made according to the next form (Tab.2).

Table 2. Consolidated assessment of the cost of project operations (planned).

\begin{tabular}{|c|c|c|c|c|c|}
\hline $\begin{array}{c}\text { Operation } \\
\text { number }\end{array}$ & $\begin{array}{c}\text { Direct } \\
\text { costs }\end{array}$ & $\begin{array}{c}\text { Additional } \\
\text { costs }\end{array}$ & Reserve & $\begin{array}{c}\text { Total cost } \\
\text { estimate }\end{array}$ & Notes \\
\hline & & & & & \\
\hline
\end{tabular}

The formation of a reserve of expenses at the stage of pilot implementation of this methodology can vary and reach up to $30 \%$. In the future, the practice of forming and accounting for costs can allow for more accurate forecasting of costs and reduce the amount of the reserve to $10 \%$.

The need for cost accounting arises from the requirement of control over the cost of the project, which, as an object of cost accounting, is subject to the influence of factors causing deviations from planned indicators. Monitoring the project costs involves constant observation of several indicators, managing changes during the project implementation, support in making the most effective management decisions, informing all interested parties about the compliance of the actual project cost indicators with the planned values. The accounting component of the project cost is defined as the actual estimate of the cost of work performed and resources expended. Using the developed volume method, the ratio of actual costs to the volume of work that must be completed by a certain date is determined. This method takes into account the time factor, which makes it possible to evaluate both the actual deviation in costs and the lag or lead in the work schedule. The use of the accrued volume method imposes additional requirements on the Customer's management accounting and reporting system. First, it is necessary to establish additional structuring of project costs, the introduction of the necessary analytical levels, the coding of cost items, to create the conditions for the collection of necessary information, including the introduction of changes to job descriptions and the modification of the motivation system to obtain timely and accurate evidence during the implementation of the project. The implementation of the developed volume method is shown in Fig. 2. in the form of a diagram with relevant actual and planned data. 
The following indicators are analyzed:

- planned project budget (BAC);

- planned cost of the planned work or the planned volume (PV) for a specific date;

- planned cost of the work performed or the disbursed volume (EV) at a specific date;

- actual cost of the work performed (AS) on a specific date;

- deviation in terms of time (SV) is determined by the formula $S V=E V-P V$;

- deviation in cost $(\mathrm{CV})$ is determined by the formula $C V=E V-A C$;

- timing deviation index or the schedule fulfillment index (SPI) is determined by the formula $S P I=E V / P V$, characterizes the degree of achievement of the project indicators in terms of the amount of work and the implementation of the project schedule;

- cost development index (CPI) is determined by the formula $\mathrm{CPI}=\mathrm{EV} / \mathrm{AC}$, characterizes the efficiency of spending money in the project;

- completion forecast (EAC) is determined by the formula $\mathrm{EAC}=\mathrm{BAC} / \mathrm{CPI}$.

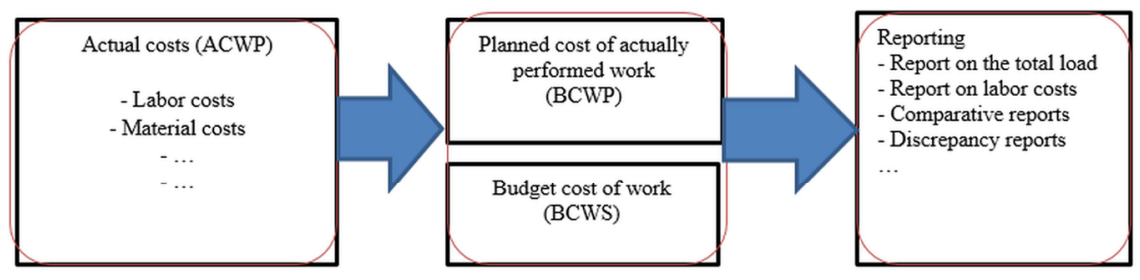

Fig. 2. Scheme of application of the developed volume method for cost control when performing a range of geotechnical monitoring works.

Monitoring and determination of the listed project indicators are recommended with the following documentary form (Tab. 3).

Table 3. Project costs monitoring on a specific date.

\begin{tabular}{|l|l|l|l|}
\hline \multicolumn{1}{|c|}{ Costs } & $\begin{array}{c}\text { Planned } \\
\text { volume } \\
\text { (PV) }\end{array}$ & $\begin{array}{c}\text { Developed } \\
\text { volume } \\
\text { (EV) }\end{array}$ & $\begin{array}{c}\text { Actual cost of } \\
\text { work performed } \\
\text { (AC) }\end{array}$ \\
\hline Direct labor costs & & & \\
\hline $\begin{array}{l}\text { Contributions to the Social Insurance Fund } \\
\text { and insurance premiums as a percentage of } \\
\text { direct labor costs }\end{array}$ & & & \\
\hline $\begin{array}{l}\text { Material costs (purchase and write-off of } \\
\text { devices worth less than 100 thousand } \\
\text { rubles for monitoring) }\end{array}$ & & & \\
\hline $\begin{array}{l}\text { Travel expenses for business trips at the } \\
\text { place of work }\end{array}$ & & & \\
\hline $\begin{array}{l}\text { Expenses for the placement of the brigade } \\
\text { at the place of business trip for surveys }\end{array}$ & & & \\
\hline $\begin{array}{l}\text { Rental of property used for the } \\
\text { implementation of the project }\end{array}$ & & & \\
\hline Food expenditures & & & \\
\hline Payment for third-party services & & & \\
\hline The total cost & & \\
\hline Timing Deviation (SV) & & \\
\hline Cost deviation (CV) & & \\
\hline Schedule Execution Index (SPI) & & \\
\hline Cost Development Index (CPI) & & \\
\hline Completion forecast (EAC) & & \\
\hline
\end{tabular}

To calculate the direct cost of labor for each project, it is possible to maintain separate reporting forms for each employee involved in projects (Tab. 4). 
Table 4. Individual report on employment in projects for the month.

\begin{tabular}{|l|l|l|l|l|l|}
\hline \multicolumn{1}{|c|}{ Indicators } & Date & Project 1 & Project 2 & Project 3 & Project 4 \\
\hline Working hours & & & & & \\
\hline Working hours & & & & & \\
\hline Working hours & & & & & \\
\hline
\end{tabular}

After the reporting month, the project manager compiles the data from the individual employment reports in the projects on the basis of hourly payment rates into the table for monitoring project costs. Developed Volume - BCWP (Budgeting Cost of Work Performed)

In this case, the deviation in costs represents the difference between the actual and planned costs of the work performed. A deviation from the schedule is determined by the difference between the planned cost of the work on the schedule and the planned cost of the work performed. The analytical reporting system used to analyze the state of the costs of the project, as a rule, contains the following indicators (table 5):

Table 5. Project cost analysis metrics.

\begin{tabular}{|l|l|}
\hline Indicator & Indicator calculation \\
\hline Planned Cost of Actual Work (BCWP) & $\begin{array}{l}B C W P=\text { Planned Cost, \% of resource } \\
\text { utilization }\end{array}$ \\
\hline Total Budget Cost (BC) & The full cost of the project budget \\
\hline Budget Value (BCWS) & $\begin{array}{l}\text { BCWS }=\mathrm{BC} * \% \text { according to the plan for the } \\
\text { current date }\end{array}$ \\
\hline Actual Costs (ACWP) & Actual costs for the current date \\
\hline Cost Development Index (CPI) & $C P I=B C W P / A C W P$ \\
\hline Cost Deviation (CV) & $C V=A C W P-B C W P$ \\
\hline Valuation before completion & Expert forecast \\
\hline Estimation of costs until completion & $A C W P+$ Valuation until Completion \\
\hline Deadline Performance Index (SPI) & SPI = BCWP / BCWS \\
\hline Cost discrepancies & $B C-$ Estimation of costs to completion \\
\hline Cost Percentage & Cost Discrepancies / BC \\
\hline
\end{tabular}

To analyze the project using the developed volume method, it is necessary to provide periodic, timely and comparable provision of data from the level of the functional managerial link on labor costs, materials, other direct costs, etc., i.e. a detailed analysis of the cost structure is needed. For reporting deviations in connection with the analysis, the use of the form is recommended (Tab. 6).

Table 6. Project deviation.

\begin{tabular}{|c|c|c|c|c|c|c|}
\hline $\begin{array}{c}\text { Operation } \\
\text { number }\end{array}$ & $\begin{array}{c}\text { Operation } \\
\text { name }\end{array}$ & $\begin{array}{c}\text { Planned } \\
\text { expense }\end{array}$ & $\begin{array}{c}\text { Actual } \\
\text { consumption }\end{array}$ & Deviation & $\begin{array}{c}\text { Main } \\
\text { reason }\end{array}$ & $\begin{array}{c}\text { Response } \\
\text { measures }\end{array}$ \\
\hline & & & & & & \\
\hline
\end{tabular}

Carrying out the analysis of the project according to the method of utilized volume provides the necessary information for assessing the current situation of the project, including the ratio of actual indicators to planned ones in terms of time and cost. The consistent use of analysis methods allows us to identify trends in the course of the project and to forecast the impact of these trends on individual stages of the project and the project as a whole.

\section{Conclusion}

Pricing in organizations performing geotechnical monitoring is based on a cost analyzing method. The optimization of the cost indicator is connected with the justified process of its 
formation and evaluation, and allows mining and constructing companies to receive stable revenue, cover costs, make investments in development and improve the quality of work performed. This chain will reasonably lead to increased efficiency in the mining industry due to the high reliability of the structures being built and a reduction in investment costs at the stage of pre-construction and construction work.

The optimal method of cost accounting for geotechnical monitoring in a company may be accounting for carriers - projects - specific geotechnical monitoring agreements concluded with customers. At the same time, monitoring the project cost is mandatory, and involves constant monitoring of project cost indicators, managing changes during the project implementation, support in making the most effective management decisions, informing all interested parties about the compliance of the actual project cost indicators with the planned values. For control, it is proposed to use the mastered volume method. The consistent use of analysis methods allows us to identify trends in the course of the project and to forecast the impact of these trends on individual stages of the project and the project as a whole.

Summarizing, we note that the proposed system for the formation and estimation of costs for geotechnical monitoring will significantly reduce the risks of mining enterprises in the acquisition of such services, as well as increase the efficiency of mining organizations. The latter is the key to ensuring the development of the industry and the sustainable socioeconomic development of mining regions.

\section{References}

1. State Estimated Norm, Reference book of base prices for measuring works and surveys of buildings and structures - SBMSB 81-02-25-2001 (Rosstroy, Moscow, 2001)

2. Collection 3.6 "Inspection and monitoring of the technical condition of building structures and engineering equipment of buildings and structures" MPP-3.6-16_(Rosstroy, Moscow, 2017)

3. A collection of basic prices for work on the examination and monitoring of the technical condition of building structures and engineering equipment, including subway structures within zones of influence of construction objects, carried out with the involvement of the budget of the city of Moscow - MPP-3.2.05.07-15 (Rosstroy, Moscow, 2017)

4. A guide for scientific and technical support and monitoring of buildings and structures under construction, including long-span, high-rise and unique-MRDS 02-08 (Rosstroy, Moscow, 2017)

5. V. Frolova, O. Dolina, T. Shpilkina, E3S Web Conf., 105, 01054 (2019)

6. O. Kalenov, S. Kukushkin, R. Kamanina, E3S Web Conf., 105, 04028 (2019)

7. O. Miliushenko, A. Kovalev, M. Zhidkova, E3S Web Conf., 105, 04046 (2019)

8 M. Anastasov, N. Kazitskaya, I. Politkovskaya, E3S Web Conf., 105, 04043 (2019)

9. O. Borisova, V. Frolova, L. Artamonova, E3S Web Conf., 105, 04047 (2019)

10. Balabanova, A., Balabanov, V., Dotsenko, E., Ezdina, N., E3S Web of Conf., 15, 04013 (2017) 